\title{
Effect of Cage in Radiological Differences between Direct and Oblique Lateral Interbody Fusion Techniques
}

\author{
Myeong Jin Ko, Seung Won Park, Young Baeg Kim \\ Department of Neurosurgery, Chung-Ang University Hospital, Seoul, Korea
}

Objective : Few studies have reported direct comparative data of lumbar spine angles between direct lateral interbody fusion (DLIF) and oblique lateral interbody fusion (OLIF). The purpose of this study was to investigate the clinical and radiological outcomes of DLIF and OLIF, and determine influential factors.

Methods : The same surgeon performed DLIF from May 2011 to August $2014(\mathrm{n}=201)$ and OLIF from September 2014 to September $2016(\mathrm{n}=142)$. Radiological parameters, cage height, cage angle (CA), cage width (CW), and cage location were assessed. We checked the cage location as the distance $(\mathrm{mm})$ from the anterior margin of the disc space to the anterior metallic indicator of the cage in lateral images.

Results : There were significant differences in intervertebral foramen height ( $\mathrm{FH} ; 22.0 \pm 2.4$ vs. $21.0 \pm 2.1 \mathrm{~mm}, p<0.001)$ and sagittal disc angle (SDA; $8.7 \pm 3.3$ vs. $\left.11.3 \pm 3.2^{\circ}, p<0.001\right)$ between the DLIF and OLIF groups at 7 days postoperatively. CA $\left(9.6 \pm 3.0\right.$ vs. $8.1 \pm 2.9^{\circ}$, $p<0.001)$ and $C W(21.2 \pm 1.6$ vs. $19.2 \pm 1.9 \mathrm{~mm}, p<0.001)$ were significantly larger in the OLIF group compared to the DLIF group. The cage location of the OLIF group was significantly more anterior than the DLIF group $(6.7 \pm 3.0$ vs. $9.1 \pm 3.6 \mathrm{~mm}, p<0.001)$. Cage subsidence at 1 year postoperatively was significantly worse in the DLIF group compared to the OLIF group $(1.0 \pm 1.5 \mathrm{vs} .0 .4 \pm 1.1 \mathrm{~mm}$, $p=0.001)$. Cage location was significantly correlated with postoperative $\mathrm{FH}(\beta=0.273, p<0.001)$ and postoperative SDA $(\beta=-0.358$, $p<0.001)$. CA was significantly correlated with postoperative $\mathrm{FH}(\beta=-0.139, p=0.044)$ and postoperative SDA $(\beta=0.236, p=0.001)$. Cage location $(\beta=0.293, p<0.001)$ and $C W(\beta=-0.225, p<0.001)$ were significantly correlated with cage subsidence.

Conclusion : The cage location, CA, and CW seem to be important factors which result in the different-radiological outcomes between DLIF and OLIF.

Key Words : Spinal fusion · Lumbar vertebrae · Instrumentation.

\section{INTRODUCTION}

Direct lateral interbody fusion (DLIF) and oblique lateral interbody fusion (OLIF) are minimally invasive techniques of lateral lumbar interbody fusion (LLIF). Both are popular for the treatment of degenerative lumbar spine disease.

DLIF passes through the psoas muscle to access the disc, while OLIF accesses the disc between the psoas muscle and prevertebral structures such as vessels and the ureter, $95,28,34,35,38$. Previous studies have been mainly related to the complications and indirect de-

- Received : June 28, 2018 •Revised : August 8, 2018 •Accepted : October 12, 2018

- Address for reprints : Seung Won Park

Department of Neurosurgery, Chung-Ang University Hospital, 102 Heukseok-ro, Dongjak-gu, Seoul 06973, Korea

Tel : +82-2-6299-3190, Fax : +82-2-6299-2069, E-mail : nspsw@cau.ac.kr, ORCID : https://orcid.org/0000-0001-8305-7501

This is an Open Access article distributed under the terms of the Creative Commons Attribution Non-Commercial License (http://creativecommons.org/licenses/by-nc/4.0) which permits unrestricted non-commercial use, distribution, and reproduction in any medium, provided the original work is properly cited. 
compression of DLIF or OLIF $1,6,11-13,16,18,20-22,30,33,34,36,38)$. However, there have been increased interests recently in postoperative lumbar spine angle which is important for the sagittal balance of the spine. Even short-level lumbar fusion can affect the overall lumbar lordosis ${ }^{2,8,14,27)}$. LLIF is also known to be very effective for coronal balance correction and reportedly for global sagittal balance $^{2,5,17,31)}$.

Although lumbar spine angles after LLIF have been studied, only a few studies have provided direct comparative data of lumbar spine angles between DLIF and OLIF, and the influential factors ${ }^{13,36)}$. In this study, we compared the clinical and radiological outcomes of DLIF and OLIF, and analyzed factors affecting the differences in the radiological outcomes between the two approaches.

\section{MATERIALS AND METHODS}

The medical records of 343 consecutive patients who underwent DLIF or OLIF at L1-L5 between May 2011 and September 2016 by a single surgeon were reviewed retrospectively. DLIF was done from May 2011 to August 2014, and OLIF was done from September 2014 to September 2016. Enrolled patients had degenerative lumbar diseases, underwent DLIF or OLIF surgery, and were followed-up for more than one year. Patients with severe spinal deformities, acute fracture, spinal metastasis, infectious spondylitis, and a history of previous lumbar fusion operations were excluded. This study was approved by the Institutional Review Board of Chung-Ang University Hospital (IRB number: 1806-004-16178).

\section{OLIF technique}

The patient was placed in a true right lateral position under general endotracheal anesthesia and fixed on the bed using plaster. After draping, the target level was located using $\mathrm{C}$-arm fluoroscopy. A transverse skin incision $(4-5 \mathrm{~cm})$ was made with its center at about $2 \mathrm{~cm}$ from the anterior margin of the target disc. The external oblique, internal oblique, and transverse abdominis muscles were dissected with a blunt manner between the muscle fibers to gain access to the retroperitoneal space. After finger dissection and retraction of the peritoneum with retroperitoneal fat, the psoas muscle could be palpated. Palpation progressed to the anterior part of the psoas muscle along the muscle surface, followed by palpation of the disc and vertebral body. The peritoneum was retracted further to see the ureter. The anterolateral part of the psoas muscle was bluntly detached from the annulus of the disc bluntly, and the tubular retractor was set up. After removal of the intervertebral disc, the contralateral annulus was opened with Cobb's elevators. Endplate preparation was done using a shaver and currette. The cage of appropriate size was inserted using an orthogonal maneuver. The trapezoid-shaped polyether ether ketone cage (Clydesdale; Medtronic, Minneapolis, MN, USA) was filled with the demineralized bone matrix (DBM, Grafton; Medtronic). Posterior fixation was done using percutaneous pedicle screw system (Longitude system; Medtronic).

\section{DLIF technique}

Under general endotracheal anesthesia, the patient was placed in a true right lateral position with lateral bending to extend space between rib and iliac crest and fixed on the bed using plaster. The process of approaching to the target disc space was the same as described in OLIF technique. Then intraoperative electromyography monitoring was used for checking the lumbosacral plexus during setting of tubular retractors at the disc space through the psoas muscle. Cage, fusion material, and posterior fixation system were the same as those used for OLIF surgery.

\section{Clinical outcomes}

Clinical outcomes were assessed using a visual analog scale (VAS) for back pain (VAS-B) and leg pain (VAS-L), as well as the Oswestry disability index (ODI). Postoperative complications were assessed by VAS and ODI measurement preoperatively and one year postoperatively.

\section{Cage parameter}

The angle (CA), height $(\mathrm{CH})$, and width $(\mathrm{CW})$ of the used cages were investigated. We measured the cage location as the distance $(\mathrm{mm})$ from the anterior margin of the disc to the anterior metallic indicator of the cage in lateral images at postoperative (Fig. 1).

\section{Radiological measurements}

Measurements made in plain radiographs included sagittal disc angle (SDA), coronal disc angle (CDA), mean disc height $(\mathrm{MDH})$, intervertebral foramen height $(\mathrm{FH})$, cage subsidence, and fusion rate. SDA, $\mathrm{CDA}, \mathrm{MDH}$, and $\mathrm{FH}$ were evaluated 


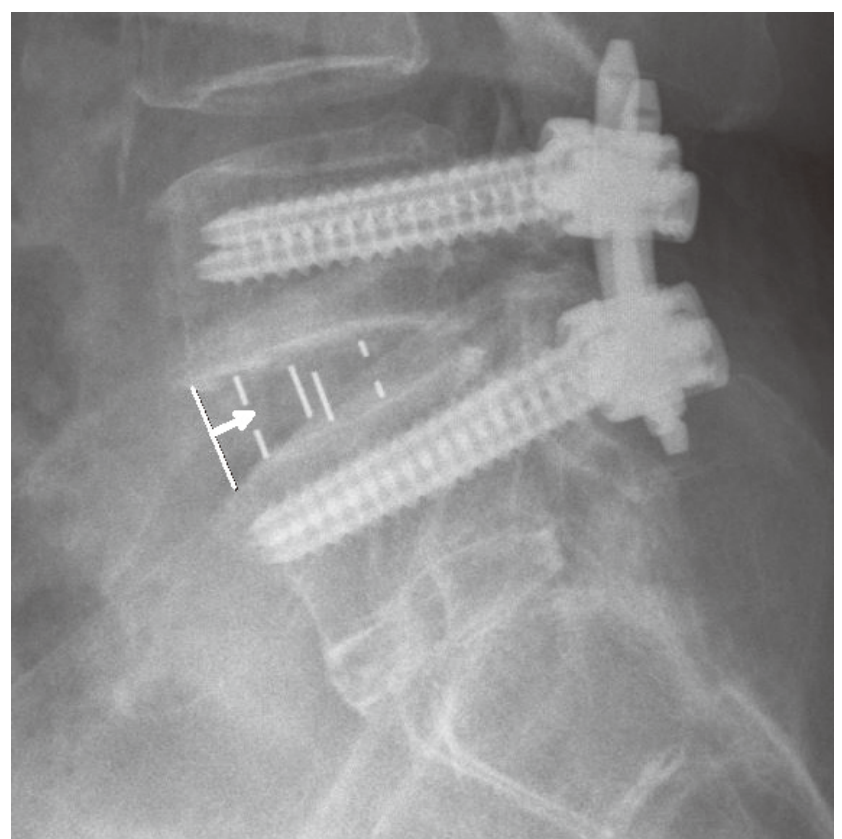

Fig. 1. As indicated by the white arrow, cage location was measured as the distance $(\mathrm{mm})$ from the anterior margin of the disc to the anterior metallic indicator of the cage in lateral image.

preoperatively, immediately after surgery, and at one year postoperatively. Cage subsidence and fusion rate were evaluated at one year after surgery.

$\mathrm{SDA}, \mathrm{CDA}, \mathrm{MDH}, \mathrm{FH}$, cage subsidence, and fusion rate were measured at each level of operation. SDA and CDA were measured by the degrees between the lower endplate of the upper vertebra and the upper endplate of the lower vertebra at each level. MDH was calculated as the mean value of anterior disc height $(\mathrm{mm})$ and posterior disc height $(\mathrm{mm})$ in lateral images. FH was measured by the distance between the inferior margin of the pedicle of the upper vertebra and the superior margin of the pedicle of the lower vertebra in the lateral view. Cage subsidence $(\mathrm{mm})$ was measured by adding the invasion depth of the lower endplate of the upper vertebral body and the invasion depth of the upper endplate of the lower vertebral body $y^{37)}$. Fusion rate was measured using the Bridwell fusion grading system (grade 1, completely remodeled with trabeculae across disc space; grade 2, graft intact with no lucent lines seen between graft and adjacent endplates; grade 3, graft intact, but a radiolucent line is seen between the graft and an adjacent endplate; and grade 4, lucency along an entire border of the graft, or lucency around a pedicle screw or subsidence of the graft $)^{4}$. Based on this classification system, grade 1-2 was determined to be successful fusion.
All radiologic measurements were made using a measuring tool of the picture archiving communication system in our hospital. Two observations were made with an interval of at least 2 weeks by two doctors, and the mean values were used for the study. The intraclass Correlation Coefficient (ICC) was checked to verify the intra-observer and inter-observer reliability of the radiologic measurements.

\section{Statistical analysis}

Radiological and clinical outcomes were compared in each group using paired t-test. Outcomes between the DLIF and OLIF groups were compared using student t-test and chisquare test. The independent effects on SDA and FH were determined using multiple regression analysis adjusted for three key factors : cage location, CA, and CW. And the independent effects on cage subsidence were determined using multiple regression analysis adjusted for nine key factors : cage location, $\mathrm{CH}, \mathrm{CW}, \mathrm{CA}$, age, gender, bone marrow density (BMD), body mass index, and surgical method (DLIF vs. OLIF). The adjusted models were developed through backward elimination with a significance level of 0.2 to enter and 0.05 to retain. A $p$ value $<0.05$ was considered statistically significant. The ICC values were graded using previously described semiquantitative criteria (excellent for values in the $0.90-1.0$ range, good for $0.70-0.89$, fair/moderate for $0.50-0.0 .69$, low for $0.25-0.49$, and poor for $0.0-0.24)$.

\section{RESULTS}

A total of 201 patients underwent DLIF surgery, and $142 \mathrm{pa}-$ tients underwent OLIF surgery. Of these, 129 patients with DLIF and 84 patients with OLIF met the criteria. Demographic data are shown in Table 1 . There were no statistically significant differences between the two groups. The intra-observer and inter-observer ICCs were $0.83-0.94$ and $0.81-0.88$, respectively (Table 2).

\section{Cage parameters}

CA (9.6 \pm 3.0 vs. $\left.8.1 \pm 2.9^{\circ}, p<0.001\right)$ and CW ( $21.2 \pm 1.6$ vs. 19.2 $\pm 1.9 \mathrm{~mm}, p<0.001$ ) were significantly larger in the OLIF group compared to the DLIF group. The cage location of the OLIF group was significantly more anterior than the DLIF group (6.7 \pm 3.0 vs. $9.1 \pm 3.6 \mathrm{~mm}, p<0.001)$. CH was not significantly 
different in the DLIF and OLIF groups $(13.3 \pm 1.3$ vs. $13.3 \pm 1.1$ $\mathrm{mm}$ ) (Table 3).

Table 1. Demographic data of the patients

\begin{tabular}{lccc}
\hline & DLIF group & OLIF group & $p$-value \\
\hline No. patient & 129 & 84 & \\
No. 3 levels operation & 5 & 5 & \\
No. 2 levels operation & 24 & 21 & \\
L2-3-4 & 0 & 2 & \\
L3-4-5 & 24 & 19 & \\
No. 1 level operation & 100 & 58 & \\
L2-3 & 2 & 3 & \\
L3-4 & 10 & 6 & \\
L4-5 & 88 & 49 & 0.056 \\
No. fusion levels & 163 & 115 & 0.422 \\
Age (years) & $61.1 \pm 12.9$ & $64.3 \pm 9.6$ & 0.205 \\
Sex ratio (male : female) & $50: 79$ & $28: 56$ & 0.706 \\
\hline BMI (kg/m ${ }^{2}$ ) & $24.7 \pm 3.9$ & $25.4 \pm 4.5$ & \\
\hline BMD (T-score) & $-0.8 \pm 1.5$ & $-0.9 \pm 1.4$ & \\
\hline Follow up period (months) & $28.6 \pm 15.7$ & $14.8 \pm 5.7$ & \\
\hline DLF : & & & \\
\hline
\end{tabular}

DLIF : direct lateral interbody fusion, OLIF : oblique lateral interbody fusion, $\mathrm{BMI}$ : body mass index, BMD : bone marrow density

Table 2. Strength of agreement of inter- and intra-observer analysis for parameters

\begin{tabular}{lcc}
\hline & Intra-observer ICC & Inter-observer ICC \\
\hline Cage location & 0.94 & 0.84 \\
MDH & 0.87 & 0.82 \\
FH & 0.84 & 0.81 \\
SDA & 0.91 & 0.88 \\
CDA & 0.90 & 0.86 \\
Fusion rate & 0.83 & 0.81 \\
\hline
\end{tabular}

ICC : The intraclass Correlation Coefficient, MDH : mean disc height, $\mathrm{FH}$ : intervertebral foramen height, SDA : sagittal disc angle, CDA : coronal disc angle

Table 3. Comparison of cages in DLIF and OLIF

\begin{tabular}{lccc}
\hline & DLIF group & OLIF group & p-value \\
\hline Cage height $(\mathrm{mm})$ & $13.3 \pm 1.3$ & $13.3 \pm 1.1$ & 0.695 \\
Cage angle $\left(^{\circ}\right)$ & $8.1 \pm 2.9$ & $9.6 \pm 3.0$ & $<0.001$ \\
Cage location $(\mathrm{mm})$ & $9.1 \pm 3.6$ & $6.7 \pm 3.0$ & $<0.001$ \\
Cage width $(\mathrm{mm})$ & $19.2 \pm 1.9$ & $21.2 \pm 1.6$ & $<0.001$ \\
\hline
\end{tabular}

DLIF : direct lateral interbody fusion, OLIF : oblique lateral interbody fusion

\section{Radiological findings}

In each group, $\mathrm{MDH}, \mathrm{FH}$, and SDA were statistically significantly increased immediately following surgery and after one year compared to the preoperative value, and CDA was significantly decreased (all $p<0.001$ ). There were significant differences between the DLIF and OLIF groups in the immediate postoperative $\mathrm{FH}(22.0 \pm 2.4$ vs. $21.0 \pm 2.1 \mathrm{~mm}, p<0.001)$, oneyear FH (21.7 \pm 2.4 vs. $20.7 \pm 2.0 \mathrm{~mm}, p=0.002)$, immediate postoperative SDA $\left(8.7 \pm 3.3\right.$ vs. $\left.11.3 \pm 3.2^{\circ}, p<0.001\right)$, and oneyear SDA ( $8.4 \pm 3.5$ vs. $\left.11.1 \pm 3.4^{\circ}, p=0.001\right)$ (Table 4$)$. Multiple regression analysis was performed to evaluate the independent effect of cage location, CA, and CW on SDA associated with sagittal balance and FH associated with indirect decompression (Tables 5 and 6). Cage location showed significantly positive correlation with immediate postoperative $\mathrm{FH}(\beta=0.273$, $p<0.001)$ and significantly negative correlation with immediate postoperative SDA $(\beta=-0.358, p<0.001)$. CA revealed significantly negative correlation with immediate postoperative

Table 4. Radiologic measurements in DLIF and OLIF groups

\begin{tabular}{|c|c|c|c|}
\hline & DLIF group & OLIF group & $p$-value \\
\hline \multicolumn{4}{|c|}{$\mathrm{MDH}(\mathrm{mm})$} \\
\hline Preop & $8.0 \pm 2.3(n=163)$ & $8.3 \pm 2.5(n=115)$ & NS \\
\hline Postop & $12.5 \pm 1.5(n=163)^{*}$ & $12.3 \pm 1.4(n=115)^{*}$ & NS \\
\hline $1 Y A$ & $12.0 \pm 1.6(n=146)^{*}$ & $12.2 \pm 1.5(n=83)^{*}$ & NS \\
\hline \multicolumn{4}{|l|}{$\mathrm{FH}(\mathrm{mm})$} \\
\hline Preop & $19.1 \pm 2.6$ & $19.5 \pm 2.8$ & NS \\
\hline Postop & $22.0 \pm 2.4^{*}$ & $21.0 \pm 2.1^{*}$ & $<0.001$ \\
\hline $1 Y A$ & $21.7 \pm 2.4^{*}$ & $20.7 \pm 2.0^{*}$ & $<0.05$ \\
\hline \multicolumn{4}{|l|}{$\operatorname{SDA}\left({ }^{\circ}\right)$} \\
\hline Preop & $4.1 \pm 3.8$ & $4.9 \pm 4.4$ & NS \\
\hline Postop & $8.7 \pm 3.3^{*}$ & $11.3 \pm 3.2^{*}$ & $<0.001$ \\
\hline $1 Y A$ & $8.4 \pm 3.5^{*}$ & $11.1 \pm 3.4^{*}$ & $<0.001$ \\
\hline \multicolumn{4}{|l|}{$\operatorname{CDA}\left({ }^{\circ}\right)$} \\
\hline Preop & $3.9 \pm 3.8$ & $3.6 \pm 3.7$ & NS \\
\hline Postop & $0.9 \pm 1.4^{*}$ & $0.8 \pm 1.2^{*}$ & NS \\
\hline $1 Y A$ & $0.9 \pm 1.2^{*}$ & $0.9 \pm 1.2^{*}$ & NS \\
\hline
\end{tabular}

Fusion rate

1 YA $\quad 89.7 \%(131 / 146) \quad 91.6 \%(76 / 83) \quad$ NS

${ }^{*} p<0.001$ comparing to preoperative value. DLIF : direct lateral interbody fusion, OLIF : oblique lateral interbody fusion, $\mathrm{P}$ : comparison between DLIF and OLIF groups, MDH : mean disc height, Preop : preoperative, NS : nonspecific, Postop : immediate postoperative, 1 YA : 1 year after surgery, $\mathrm{FH}$ : intervertebral foramen height, SDA : sagittal disc angle, CDA : coronal disc angle 
Table 5. Multiple regression analysis for the influences of cage location, angle, and width on intervertebral foramen height

\begin{tabular}{lccccccc}
\hline $\begin{array}{l}\text { Predictors of } \\
\text { postop-FH }\end{array}$ & $\begin{array}{c}\text { Unstandardized } \\
\text { coefficient }\end{array}$ & & $\begin{array}{c}\text { Standardized } \\
\text { coefficient }\end{array}$ & t-value & $\boldsymbol{p}$-value \\
\cline { 2 - 3 } Cage location & 0.180 & 0.039 & & 0.273 & 4.626 & $<0.001$ \\
Cage angle & -0.652 & 0.322 & & -0.139 & -2.023 & 0.044 \\
Cage width & -0.440 & 0.333 & & -0.095 & -1.323 & 0.187 \\
Constant & 21.761 & 0.642 & & 33.890 & $<0.001$ \\
\hline
\end{tabular}

Postop : immediate postoperative, $\mathrm{FH}$ : intervertebral foramen height, SE : standard error
Table 6. Multiple regression analysis for the influences of cage location, angle, and width on sagittal disc angle

\begin{tabular}{|c|c|c|c|c|c|}
\hline \multirow{2}{*}{$\begin{array}{l}\text { Predictors of } \\
\text { postop-SDA }\end{array}$} & \multicolumn{2}{|c|}{$\begin{array}{c}\text { Unstandardized } \\
\text { coefficient }\end{array}$} & \multirow{2}{*}{$\frac{\begin{array}{c}\text { Standardized } \\
\text { coefficient }\end{array}}{\beta}$} & \multirow[t]{2}{*}{ t-value } & \multirow[t]{2}{*}{$p$-value } \\
\hline & B & SE & & & \\
\hline Cage location & -0.680 & 0.111 & -0.358 & -6.131 & $<0.001$ \\
\hline Cage angle & 3.184 & 0.918 & 0.236 & 3.469 & 0.001 \\
\hline Cage width & -1.525 & 0.948 & -0.114 & -1.607 & 0.109 \\
\hline Constant & 20.860 & 1.830 & & 11.399 & $<0.001$ \\
\hline$R^{2}=$ & 0.173, adj & $D^{2}$ & $015<10$ & $p<0.001$ & \\
\hline
\end{tabular}

Postop : immediate postoperative, SDA : sagittal disc angle, SE : standard error
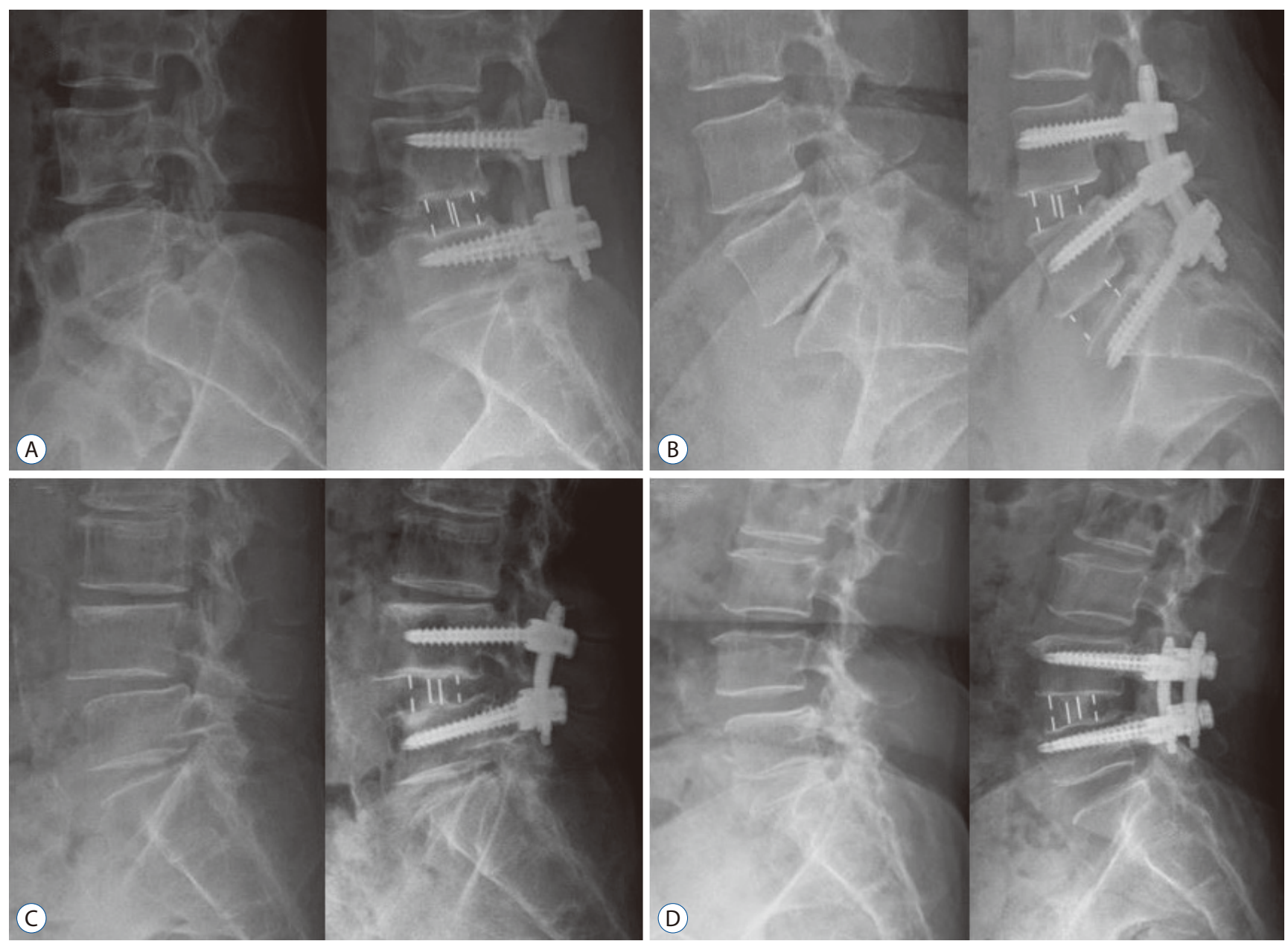

Fig. 2. Significant effect of cage location and cage angle on intervertebral FH and SDA. A: DLIF at L4-5, cage location: $13.2 \mathrm{~mm}, \mathrm{CA}: 6^{\circ}, \mathrm{CH}: 12 \mathrm{~mm}$; preoperative FH and SDA were changed from $21.2 \mathrm{~mm}$ and $1.4^{\circ}$ to $27.5 \mathrm{~mm}$ and $3.7^{\circ}$ postoperatively. $\mathrm{B}$ : OLIF at L4-5, cage location: $5.4 \mathrm{~mm}, \mathrm{CA}: 6^{\circ}, \mathrm{CH}: 12 \mathrm{~mm} ;$ preoperative FH and SDA were changed from $18.7 \mathrm{~mm}$ and $9.8^{\circ}$ to $19.2 \mathrm{~mm}$ and $13.2^{\circ}$ postoperatively. C: DLIF at L4-5, cage location: $10.6 \mathrm{~mm}, \mathrm{CA}: 12^{\circ}, \mathrm{CH}: 14 \mathrm{~mm}$; preoperative $\mathrm{FH}$ and SDA were changed from $17.9 \mathrm{~mm}$ and $5.7^{\circ}$ to $20.24 \mathrm{~mm}$ and $10.1^{\circ}$ postoperatively. D: OLIF at L4-5, cage location: $4.2 \mathrm{~mm}, \mathrm{CA}: 12^{\circ}, \mathrm{CH}: 14 \mathrm{~mm}$; preoperative $\mathrm{FH}$ and SDA were changed from $19.8 \mathrm{~mm}$ and $-1.7^{\circ}$ to $19.9 \mathrm{~mm}$ and $14.5^{\circ}$ postoperatively. $\mathrm{FH}$ : foramen height, SDA : sagittal disc angle, DLIF : direct lateral interbody fusion, $\mathrm{CA}$ : cage angle, $\mathrm{CH}$ : cage height, OLIF : oblique lateral interbody fusion. 
FH ( $\beta=-0.139, p=0.044)$ and significantly positive correlation with immediate postoperative SDA $(\beta=0.236, p=0.001$ ) (Fig. 2). CW did not show significant correlation with immediate postoperative FH and SDA. Cage subsidence after one year was $1.0 \pm 1.5$ and $0.4 \pm 1.1 \mathrm{~mm}$ in the DLIF and OLIF groups, respectively, and was significantly worse in DLIF $(p=0.001)$. Multiple regression analysis was performed on the key factors of cage subsidence between DLIF and OLIF (Table 7). Cage location $(\beta=0.293, p<0.001), \mathrm{CH}(\beta=0.236, p<0.001)$, and age ( $\beta=0.152, p=0.015)$ showed significantly positive correlation, and $\mathrm{CW}(\beta=-0.225, p<0.001)$ showed significantly negative correlation with cage subsidence. The fusion rate one year after surgery was $89.7 \%$ (131/146) and $91.6 \%$ (76/83) in the DLIF and OLIF groups, respectively, with no significant difference.

\section{Clinical outcomes}

Preoperative VAS-B and VAS-L scores in the DLIF group were $7.9 \pm 2.4$ and $5.1 \pm 1.4$, respectively. The respective scores in

Table 7. Multiple regression analysis for the influence of factors on cage subsidence

\begin{tabular}{|c|c|c|c|c|c|}
\hline \multirow{2}{*}{$\begin{array}{l}\text { Predictors } \\
\text { of cage } \\
\text { subsidence }\end{array}$} & \multicolumn{2}{|c|}{$\begin{array}{c}\text { Unstandardized } \\
\text { coefficient }\end{array}$} & \multirow{2}{*}{$\begin{array}{c}\begin{array}{c}\text { Standardized } \\
\text { coefficient }\end{array} \\
\beta\end{array}$} & \multirow[t]{2}{*}{ t-value } & \multirow[t]{2}{*}{$p$-value } \\
\hline & B & SE & & & \\
\hline Cage location & 0.118 & 0.025 & 0.293 & 4.778 & $<0.001$ \\
\hline Cage height & 0.279 & 0.069 & 0.236 & 4.064 & $<0.001$ \\
\hline Cage width & -0.648 & 0.176 & -0.225 & -3.688 & $<0.001$ \\
\hline Age & 0.020 & 0.008 & 0.152 & 2.457 & 0.015 \\
\hline BMD & -0.092 & 0.062 & -0.091 & -1.484 & 0.139 \\
\hline Constant & -4.309 & 1.031 & & -4.181 & $<0.001$ \\
\hline \multicolumn{6}{|c|}{$R^{2}=0.271$, adjusted $-R^{2}=0.254, F=16.558, p<0.001$} \\
\hline
\end{tabular}

$\mathrm{SE}$ : standard error, BMD : bone marrow density

Table 8. VAS and ODI in DLIF and OLIF groups

\begin{tabular}{lccc}
\hline & DLIF & OLIF & $\boldsymbol{p}$-value \\
\hline Preop VAS back & $7.9 \pm 2.4$ & $7.8 \pm 1.9$ & 0.475 \\
1 YA VAS back & $1.5 \pm 0.4$ & $1.4 \pm 0.5$ & 0.236 \\
Preop VAS leg & $5.1 \pm 1.4$ & $5.4 \pm 1.6$ & 0.295 \\
1 YA VAS leg & $1.1 \pm 0.5$ & $1.0 \pm 0.5$ & 0.315 \\
Preop ODI (\%) & $39.8 \pm 15.3$ & $41.1 \pm 12.9$ & 0.395 \\
1 YA ODI (\%) & $10.4 \pm 5.8$ & $11.2 \pm 4.8$ & 0.157 \\
\hline VAS : visual analog scale, ODI : Oswestry disability index, DLIF : direct \\
lateral interbody fusion, OLIF : oblique lateral interbody fusion, Preop : \\
preoperative, 1 YA : 1 year after surgery
\end{tabular}

the OLIF group were $7.8 \pm 1.9$ and $5.4 \pm 1.6$. VAS-B and VAS-L scores after one year were $1.5 \pm 0.4$ and $1.1 \pm 0.5$, respectively, in the DLIF group and $1.4 \pm 0.5$ and $1.0 \pm 0.5$, respectively, in the OLIF group. Preoperative ODI values in the DLIF and OLIF groups were $39.8 \pm 15.3 \%$ and $41.1 \pm 12.9 \%$, respectively. The respective values after one year in the DLIF and OLIF groups were $10.4 \pm 5.8 \%$ and $11.2 \pm 4.8 \%$. In both groups, the VAS and ODI scores improved significantly after surgery compared with before surgery $(p<0.001)$. There were no significant differences in VAS and ODI scores between the DLIF and OLIF groups (Table 8). Overall, there were 21 (16.3\%) complications in the DLIF group and $12(14.3 \%)$ in the OLIF group. In the DLIF group, complications involved the psoas muscle symptoms in 13 patients (10.1\%), lateral femoral cutaneous nerve symptoms in four patients (3.1\%), paralytic ileus in two patients $(1.6 \%)$, and the genitofemoral nerve symptoms in two patients (1.6\%). In the OLIF group, nine patients (10.7\%) showed paralytic ileus, two patients $(2.4 \%)$ showed psoas muscle symptoms, and one patient (1.2\%) showed genitofemoral nerve symptoms (Table 9). The total complication rate was not significantly different between the DLIF and OLIF groups. However, psoas muscle symptoms were more significantly frequent in the DLIF group ( $p=0.023$ ), and paralytic ileus was more significantly common in the OLIF group ( $p=0.005)$. All complications resolved within several weeks. There was no lumbar plexus injury, ureter injury, and infection in DLIF and OLIF surgery. And there was no case of revision surgery due to complication or incomplete surgery in both groups.

\section{DISCUSSION}

Both DLIF and OLIF are surgical methods that can improve

Table 9. Overall complications in DLIF and OLIF group

\begin{tabular}{lcc}
\hline Complications & DLIF & OLIF \\
\hline Psoas muscle symptom* $^{*}$ & $13(10.1)$ & $2(2.4)$ \\
Lateral femoral cutaneous nerve symptom & $4(3.1)$ & $0(0.0)$ \\
Genitofemoral nerve symptom & $2(1.6)$ & $1(1.2)$ \\
Paralytic ileus* & $2(1.6)$ & $9(10.7)$ \\
Total & $21(16.3)$ & $12(14.3)$ \\
\hline
\end{tabular}

Values are presented as number (\%). ${ }^{*} p<0.05$. DLIF : direct lateral interbody fusion, OLIF : oblique lateral interbody fusion 
the segmental coronal and sagittal angles using a long and large cage $e^{2,17,18,21,31,33)}$. Similar to previous studies, the DLIF and OLIF groups presently showed a statistically significant improvement in SDA and CDA after surgery. There was no significant difference in CDA between the two groups, indicating that the CDA does not differ according to the surgical procedure, CA, and cage location. In both DLIF and OLIF, the coronal balance was well corrected because the cage was positioned over bilateral ends of the vertebral body.

The difference in the CA between DLIF and OLIF groups was largely reflected availability of the $12^{\circ}$ cage in Korea (from August 2013). However, OLIF seemed to be more advantageous than DLIF in positioning the cage location by the operator's intention. We have tried to insert cages anteriorly because the anterior cage location was known to make the sagittal angle larger ${ }^{15,30)}$. With DLIF, it was difficult to estimate the cage location through the tubular retractor due to the limited visualization of anterior disc margin which could be a kind of landmark for cage location. However, since the anterior disc margin can be directly identified during OLIF, it is more advantageous to position the cage anteriorly. The more anterior annulotomy and discectomy seemed to secure higher anterior disc space for the high angle cage with greater anterior height, which also might affect the more frequent use of higher angle cage in the OLIF group.

Our results on the relationship between the cage location and sagittal angle are similar to previous reports ${ }^{15,30)}$. Kepler et al. ${ }^{15)}$ used $10^{\circ}$ lordotic cages and reported that the increase in lumbar lordosis was greatest when the cage was placed in the anterior portion of the disc space $\left(+7.4^{\circ}\right.$ lordosis per level) and less when it was placed in the midportion of the disc $\left(+3.8^{\circ}\right.$ lordosis per level). Park et al. ${ }^{30)}$ used $6^{\circ}$ lordotic cages and reported sagittal angles were significantly greater in the anterior group $\left(6.1^{\circ}\right)$ than those of the middle group $\left(2.4^{\circ}\right)$. Our data showed similar results increasing the sagittal angle by placing the cage more anteriorly. Although the two studies evaluated the cage location in three places (anterior, middle, posterior), we measured the distance from the anterior disc margin to the anterior metallic indicator of the cage. We used the metallic indicator to increase the accuracy of measurement.

Regarding the relationship between CA and SDA, Barone et al..$^{3)}$ reported that postoperative SDA was $6.5^{\circ}$ when using $10^{\circ}$ lordotic cages, while postoperative SDA was $13.2^{\circ}$ when $20^{\circ}$ lordotic cages were used. This result is similar to our findings that SDA measured $7.3 \pm 2.4^{\circ}$ when using $6^{\circ}$ lordotic cages and $11.8 \pm 3.5^{\circ}$ when using $12^{\circ}$ lordotic cages, but the postoperative angles were larger than previous studies. These might be the result of attempting to make a larger sagittal angle by the posterior shortening as much as possible with rod compression, as well as by placing the cage in the anterior location and using a more lordotic cage (Fig. 3).

Although both cage location and CA were important factor for SDA, the cage location $(\beta=-0.358)$ was more influential to SDA than CA $(\beta=0.236)$. The more anteriorly the cage is located, the larger the disc space behind the cage was made, which can contribute to the disc angle by acting as a sufficient lever length during the posterior shortening with rod compression. On the other hand, when the cage is placed in the posterior, there is a little disc space behind the cage to serve as a lever. Therefore, it seems that posterior shortening itself is not sufficient to make a disc angle without sufficient disc space behind the cage.

Previous studies on the indirect decompression of LLIF have reported a significant increase in $\mathrm{FH}$ (or foraminal area [FA]) and cross-sectional area (CSA) of the thecal sac compared to before surgery ${ }^{10,11,16,21,23,26,30)}$. The cage location itself was reported not to affect the FA and $\mathrm{CSA}^{16,35)}$. However, on the contrary, $\mathrm{FH}$ increased as the cage was placed more poste-
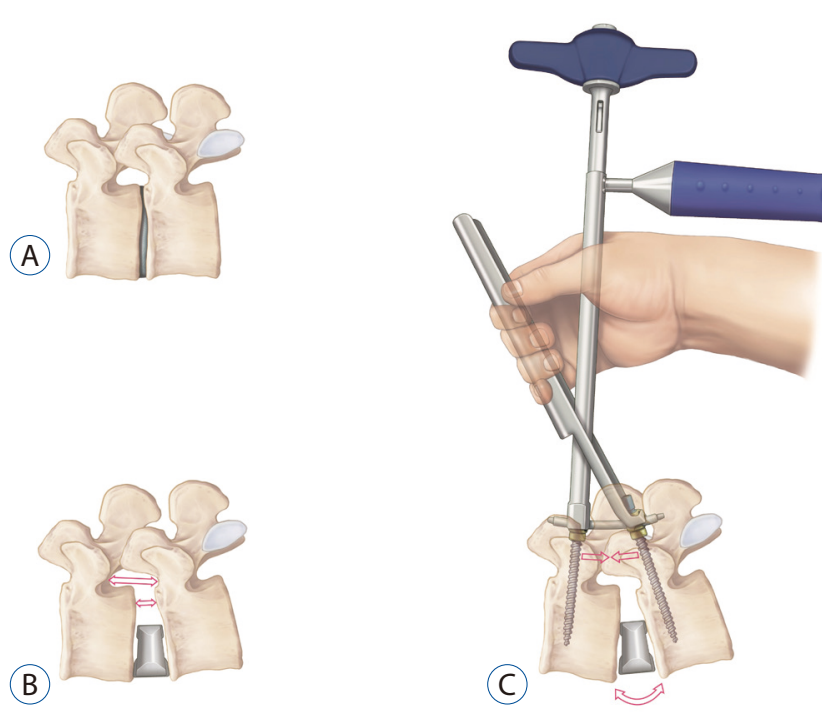

Fig. 3. Cage insertion increases the heights of disc space and intervertebral foramen (B) compared to the preoperative state $(A)$, then an additional sagittal angle can be made by posterior shortening with percutaneous rod compressor (C). 
riorly and as the CA decreased according to our data. Although we measured $\mathrm{FH}$ rather than FA, FH and FA have been strongly correlated ${ }^{30)}$. Thus, FH can be considered to reflect the size of FA closely. As a result, both the cage location and CA seem to be important factors for selection of surgical purpose, sagittal angle or indirect decompression, by a surgeon. Accordingly, posterior cage location and smaller CA should be selected to maximize the indirect decompression, and anterior cage location and larger CA should be selected to maximize the sagittal angle.

Age, $\mathrm{BMD}, \mathrm{CW}$, and taller $\mathrm{CH}$ are factors that reportedly affect cage subsidence in lumbar interbody fusion ${ }^{7,18,19,24,29,32,37)}$. In our study, cage subsidence increased with a more posterior cage location $(\beta=0.293)$, taller $\mathrm{CH}(\beta=0.236)$, smaller $\mathrm{CW}$ ( $\beta=-0.225)$, and older age $(\beta=0.152)$. The cage location was revealed as a very meaningful factor for subsidence, which was not mentioned in previous studies $7,18,19,24,29,32,37)$. One recent study reported that the contact area between the cage and the epiphyseal ring significantly influences the cage subsidence rather than the endplate violation during $L_{L I F}{ }^{5)}$. The cage used in our study is long enough to contact the epiphyseal ring at both sides. Moreover, since the vertebral body has a round surface, the contact area with the epiphyseal ring increases as the cage is located more anteriorly. As a result, it seems that a long cage inserted anteriorly in the disc space can reduce the subsidence by increasing mechanical support. Those cage related characteristics increasing the mechanical strength in the DLIF and OLIF seem to relate to the phenomenon, BMD did not have an effect on subsidence in our study.

Fusion rates in our study were not significantly different between the two groups.

Clinical outcomes (VAS, ODI) in DLIF and OLIF were improved significantly after surgery. However, there was no significant difference in clinical outcome between the two groups, which was similar to a recent study ${ }^{13)}$.

Complications seemed to be related with the surgical approaches, increased psoas symptom in the DLIF due to transpsoas approach and increased ileus in the OLIF due to more peritoneal retraction.

In this study, the cage location and CA affected radiologic outcomes of FH and SDA, and the cage location and CW were related to cage subsidence. However, it is still too early to generalize because of the insufficient number of patients in our study. Additional long-term, large-scale, and prospective stud- ies are needed. Although the use of a high angle cage inserting anteriorly in the disc space seemed to increase disc angle effectively, it cannot be a direct evidence of the practical help for deformity correction in patients with sagittal imbalance.

\section{CONCLUSION}

Both DLIF and OLIF are useful surgical methods to improve the radiological and clinical outcomes in degenerative lumbar disease. OLIF was more effective in increasing sagittal angle and reducing cage subsidence, but was disadvantageous for indirect decompression than DLIF. The cage location, CA and CW seem to be important factors which result in the different-radiological outcomes between DLIF and OLIF. Surgeons should carefully choose cage location and CA to satisfy sagittal balance and indirect decompression when performing DLIF and OLIF.

\section{CONFLICTS OF INTEREST}

No potential conflict of interest relevant to this article was reported.

\section{INFORMED CONSENT}

Informed consent was obtained from all individual participants included in this study.

\section{AUTHOR CONTRIBUTIONS}

\author{
Conceptualization : MJK, SWP \\ Data curation : MJK \\ Formal analysis : MJK \\ Methodology : SWP, YBK \\ Project administration : SWP \\ Visualization : MJK \\ Writing - original draft : MJK \\ Writing - review \& editing : MJK, SWP, YBK
}




\section{References}

1. Abe K, Orita S, Mannoji C, Motegi H, Aramomi M, Ishikawa T, et al. : Perioperative complications in 155 patients who underwent oblique lateral interbody fusion surgery: perspectives and indications from a retrospective, multicenter survey. Spine (Phila Pa 1976) 42 : 55-62, 2017

2. Acosta FL, Liu J, Slimack N, Moller D, Fessler R, Koski T : Changes in coronal and sagittal plane alignment following minimally invasive direct lateral interbody fusion for the treatment of degenerative lumbar disease in adults: a radiographic study. J Neurosurg Spine 15 : 92-96, 2011

3. Barone G, Scaramuzzo L, Zagra A, Giudici F, Perna A, Proietti L : Adult spinal deformity: effectiveness of interbody lordotic cages to restore disc angle and spino-pelvic parameters through completely mini-invasive trans-psoas and hybrid approach. Eur spine J 26(Suppl 4) : 457-463, 2017

4. Bridwell KH, Lenke LG, McEnery KW, Baldus C, Blanke K : Anterior fresh frozen structural allografts in the thoracic and lumbar spine. Do they work if combined with posterior fusion and instrumentation in adult patients with kyphosis or anterior column defects? Spine (Phila Pa 1976) 20 : 1410-1418, 1995

5. Briski DC, Goel VK, Waddell BS, Serhan H, Kodigudla MK, Palepu V, et al. : Does spanning a lateral lumbar interbody cage across the vertebral ring apophysis increase loads required for failure and mitigate endplate violation. Spine (Phila Pa 1976) 42 : E1158-E1164, 2017

6. Chang J, Kim JS, Jo H : Ventral dural injury after oblique lumbar interbody fusion. World Neurosurgery 98 : 881.e1-881.e4, 2017

7. Cheung KM, Zhang YG, Lu DS, Luk KD, Leong JC : Reduction of disC space distraction after anterior lumbar interbody fusion with autologous iliac crest graft. Spine (Phila Pa 1976) 28 : 1385-1389, 2003

8. Cho JH, Joo YS, Lim C, Hwang CJ, Lee DH, Lee CS : Effect of one- or two-level posterior lumbar interbody fusion on global sagittal balance. Spine J 17 : 1794-1802, 2017

9. Davis TT, Hynes RA, Fung DA, Spann SW, MacMillan M, Kwon B, et al. : Retroperitoneal oblique corridor to the L2-S1 intervertebral discs in the lateral position: an anatomic study. J Neurosurg Spine 21 : 785-793, 2014

10. Elowitz EH, Yanni DS, Chwajol M, Starke RM, Perin NI : Evaluation of indirect decompression of the lumbar spinal canal following minimally invasive lateral transpsoas interbody fusion: radiographic and outcome analysis. Minim Invasive Neurosurg 54 : 201-206, 2011

11. Fujibayashi S, Hynes RA, Otsuki B, Kimura H, Takemoto M, Matsuda S: Effect of indirect neural decompression through oblique lateral interbody fusion for degenerative lumbar disease. Spine (Phila Pa 1976) 40 : E175-E182, 2015

12. Hijji FY, Narain AS, Bohl DD, Ahn J, Long WW, DiBattista JV, et al. : Lateral lumbar interbody fusion: a systematic review of complication rates. Spine J 17 : 1412-1419, 2017

13. Jin J, Ryu KS, Hur JW, Seong JH, Kim JS, Cho HJ : Comparative study of the difference of perioperative complication and radiologic results: MISDLIF (minimally invasive direct lateral lumbar interbody fusion) versus MIS-OLIF (minimally invasive oblique lateral lumbar interbody fusion).
Clin Spine Surg 31 : 31-36, 2018

14. Johnson RD, Valore A, Villaminar A, Comisso M, Balsano M : Pelvic parameters of sagittal balance in extreme lateral interbody fusion for degenerative lumbar disc disease. J Clin Neurosci 20 : 576-581, 2013

15. Kepler CK, Huang RC, Sharma AK, Meredith DS, Metitiri O, Sama AA, et al. : Factors influencing segmental lumbar lordosis after lateral transpsoas interbody fusion. Orthop Surg 4 : 71-75, 2012

16. Kepler CK, Sharma AK, Huang RC, Meredith DS, Girardi FP, Cammisa FP Jr, et al. : Indirect foraminal decompression after lateral transpsoas interbody fusion. J Neurosurg Spine 16 : 329-333, 2012

17. Kim JS, Lee HS, Shin DA, Kim KN, Yoon DH : Correction of coronal imbalance in degenerative lumbar spine disease following direct lateral interbody fusion (DLIF). Korean J Spine 9 : 176-180, 2012

18. Kim SJ, Lee YS, Kim YB, Park SW, Hung VT : Clinical and radiological outcomes of a new cage for direct lateral lumbar interbody fusion. Korean J Spine 11 : 145-151, 2014

19. Le TV, Baaj AA, Dakwar E, Burkett CJ, Murray G, Smith DA, et al. : Subsidence of polyetheretherketone intervertebral cages in minimally invasive lateral retroperitoneal transpsoas lumbar interbody fusion. Spine (Phila Pa 1976) 37 : 1268-1273, 2012

20. Lee HJ, Kim JS, Ryu KS, Park CK : Ureter injury as a complication of oblique lumbar interbody fusion. World Neurosurgery 102 : 693.e7693.e14, 2017

21. Lee YS, Park SW, Kim YB : Direct lateral lumbar interbody fusion: clinical and radiological outcomes. J Korean Neurosurg Soc 55 : 248-254, 2014

22. Li JX, Phan K, Mobbs R : Oblique lumbar interbody fusion: technical aspects, operative outcomes, and complications. World Neurosurgery 98 : 113-123, 2017

23. Malham GM, Parker RM, Goss B, Blecher CM, Ballok ZE : Indirect foraminal decompression is independent of metabolically active facet arthropathy in extreme lateral interbody fusion. Spine (Phila Pa 1976) 39 : E1303-E1310, 2014

24. Marchi L, Abdala N, Oliveira L, Amaral R, Coutinho E, Pimenta L : Radiographic and clinical evaluation of cage subsidence after stand-alone lateral interbody fusion. J Neurosurg Spine 19 : 110-118, 2013

25. McAfee PC, Regan JJ, Geis WP, Fedder IL : Minimally invasive anterior retroperitoneal approach to the lumbar spine. Emphasis on the lateral BAK. Spine (Phila Pa 1976) 23 : 1476-1484, 1998

26. Oliveira L, Marchi L, Coutinho E, Pimenta $L$ : A radiographic assessment of the ability of the extreme lateral interbody fusion procedure to indirectly decompress the neural elements. Spine (Phila Pa 1976) 35(26 Suppl) : S331-S337, 2010

27. Ould-Slimane M, Lenoir T, Dauzac C, Rillardon L, Hoffmann E, Guigui P, et al. : Influence of transforaminal lumbar interbody fusion procedures on spinal and pelvic parameters of sagittal balance. Eur Spine J 21 : 1200-1206, 2012

28. Ozgur BM, Aryan HE, Pimenta L, Taylor WR : Extreme lateral interbody fusion (XLIF): a novel surgical technique for anterior lumbar interbody fusion. Spine J 6 : 435-443, 2006

29. Park SH, Park WM, Park CW, Kang KS, Lee YK, Lim SR : Minimally inva- 
sive anterior lumbar interbody fusion followed by percutaneous translaminar facet screw fixation in elderly patients. J Neurosurg Spine 10 : 610-616, 2009

30. Park SJ, Lee CS, Chung SS, Kang SS, Park HJ, Kim SH : The ideal cage position for achieving both indirect neural decompression and segmental angle restoration in lateral lumbar interbody fusion (LLIF). Clin Spine Surg 30 : E784-E790, 2017

31. Phan K, Rao PJ, Scherman DB, Dandie G, Mobbs RJ : Lateral lumbar interbody fusion for sagittal balance correction and spinal deformity. J Clin Neurosci 22 : 1714-1721, 2015

32. Satake K, Kanemura T, Yamaguchi H, Segi N, Ouchida J : Predisposing factors for intraoperative endplate injury of extreme lateral interbody fusion. Asian Spine J 10 : 907-914, 2016

33. Sharma AK, Kepler CK, Girardi FP, Cammisa FP, Huang RC, Sama AA : Lateral lumbar interbody fusion: clinical and radiographic outcomes at 1 year: a preliminary report. J Spinal Disord Tech 24 : 242-250, 2011

34. Silvestre C, Mac-Thiong JM, Hilmi R, Roussouly P : Complications and morbidities of mini-open anterior retroperitoneal lumbar interbody fusion: oblique lumbar interbody fusion in 179 patients. Asian Spine J 6 : 89-97, 2012

35. St Clair S, Tan JS, Lieberman I : Oblique lumbar interbody fixation: a biomechanical study in human spines. J Spinal Disord Tech 25 : 183189, 2012

36. Tempel ZJ, Gandhoke GS, Bonfield CM, Okonkwo DO, Kanter AS : Radiographic and clinical outcomes following combined lateral lumbar interbody fusion and posterior segmental stabilization in patients with adult degenerative scoliosis. Neurosurg Focus 36 : E11, 2014

37. Tokuhashi Y, Ajiro Y, Umezawa N : Subsidence of metal interbody cage after posterior lumbar interbody fusion with pedicle screw fixation. Orthopedics 32, 2009

38. Woods KR, Billys JB, Hynes RA : Technical description of oblique lateral interbody fusion at L1-L5 (OLIF25) and at L5-S1 (OLIF51) and evaluation of complication and fusion rates. Spine J 17 : 545-553, 2017 